\title{
sciendo
}

Int. J. of Applied Mechanics and Engineering, 2021, vol.26, No.3, pp.1-11

DOI: 10.2478/ijame-2021-0031

\section{NUMERICAL THERMO-MECHANICAL STRENGTH ANALYSIS OF AN IC ENGINE COMPONENT}

\author{
M.A.N.ALI*, R.A. HUSSEIN and H.A. HUSSEIN \\ Middle Technical University, Technical Engineering College - Baghdad, IRAQ \\ E-mail: maaltememy69@yahoo.com
}

\begin{abstract}
This research investigates a thermo-mechanical strength of three geometrical shape designs of an internal combustion (IC) engine piston by a finite element analysis (FEA). FEA was performed using Solidworks software for modelling geometrical piston designs, and the models were imported into ANSYS software for thermo-mechanical fatigue simulation. The work focused on predicting high stress intensity and indicated the fatigue critical regions and life of the piston shape design. AL7075-T6 aluminium alloy was used as a piston material and thermo-mechanical fatigue simulation was conducted based on the experimental stress-number of cycles recorded data from literature. Analytical results showed the similarity of the critical failure positions to some real failures in the IC engine piston, and the shape design modification of the piston. Hence, this concept can be used to satisfy the IC engine design needs at low cost.
\end{abstract}

Key words: numerical analysis, IC engine piston, geometrical shape, thermo-mechanical strength, stress intensity and fatigue life

\section{Introduction}

In recent years, scholars have focused on the development of internal combustion engines based on their kind or uses. Each manufacturer attempts to evolve their own engine to emulate for a new technology or invention. In an IC engine, the piston is one of the important components and is formed as a cylindrical part moving up and down in the cylinder bore due to the hot gas pressure produced by the explosion. This mechanism transfers the resultant force to the crankshaft via the piston rod, so the crank turns. The features of the piston are classified into: piston head, pin and pin bore, skirt, ring land, ring groove and piston ring. Basically, the shape of the piston depends on the engine design and is usually different at the crown design. The piston is one of the most stressed components of the IC engine. The piston may suffer many damages or failures caused by high pressure and heat, especially parts like: piston skirt seizing, head seizing, ring damage, cracking edges and others. The regions and value of stresses that produce these damages can be predicted and determined by numerical FEA simulation.

Many researchers have studied the stress distribution of the piston under the actual engine operating conditions. Vaishali and Nitin et al. conducted thermal, mechanical and thermo-mechanical analyses; they predicted that variable types of stresses exerted on the top surface of the piston may cause damage or failure under the operating conditions $[1,2]$. Lokesh Singh et al., presented a research on a three-dimensional solid model of a piston that included a piston pin designed with CATIA and Solidworks software to analyse the thermal, mechanical and thermo-mechanical stress distribution and deformation for an aluminium silicon composite piston [3]. Sandeep and Vishnu studied and analysed a piston of a four-stroke engine under thermal and principal stresses by using FEM [4]. Mallavarapu and Vijaya used ANSYS software to study the static and thermal stresses on the piston made of an aluminium alloy coated with zirconium and $M g S i$ instead of silicon to develop thermal conditions and total deformation. They concluded that adding zirconium and $\mathrm{MgSi}$ produced better results [5]. Andoko and Poppy investigated the effects of high pressure and

\footnotetext{
*To whom correspondence should be addressed
} 
temperature on the piston surface by using ANSYS software and found that different pressures applied to the piston surface changed the grade of pressure experienced by the piston [6]. Cioata et al. studied stresses and displacement distribution due to flue gas pressure and temperature combined and separated by using FEA. They compared the FEA results and data obtained by analytical methods. The final results showed that the obtained values are very close to stress values [7]. Manish Kumar studied the thermal and mechanical stress distributions on an aluminium piston by using ANSYS software. The researcher generated a range of maximum and minimum temperatures distributed on the piston as well as heat flux on the piston crown. The combined mechanical and thermal stresses were calculated [8]. Valentin compared static and thermal stresses endured for two types of piston materials, namely, aluminium6061 alloys and grey cast iron, by using software to estimate the maximum temperature, minimum von Mises stress and minimum value of deformation registered in the piston alloys [9]. Sayed et al. selected two types of piston materials, $A l$ alloy and $\mathrm{Ti}$ alloy which were coated with $\mathrm{Ni}-\mathrm{Cr}-\mathrm{Al}$ and $\mathrm{Mg}-\mathrm{Zr}-\mathrm{O}_{3}$ materials. Heat flux distribution for different combinations of piston and coating materials was studied. The results were presented graphically, and a comparison was made, indicating that $M g$ alloy coating was preferable [10]. Ajay et al. performed a thermal analysis on a conventional diesel engine piston made of multiple materials at different times. FEA was carried out to indicate the thermal and mechanical load effects on the top surface of the piston, where data obtained can increase the life of the piston [11].

This study presents a numerical investigation based on modelling and simulation for a selected IC engine component utilising ANSYS software. The numerical analysis aimed to examine the thermomechanical strength of different shape designs of an IC engine piston based on the experimental isothermal fatigue data obtained under elevated temperature.

\section{Numerical analysis}

A numerical thermo-mechanical stress and fatigue analysis was conducted for different geometrical models of the IC engine piston by employing finite element simulation using ANSYS Workbench version 16.1. This numerical simulation was based on the combination of thermal and mechanical loading in steady state applied to the piston. Thermo-mechanical fatigue analysis was performed, depending on a practical isothermal low cycle fatigue life testing under bending loading with constant high temperature for the selected material of the piston.

\subsection{Piston geometrical modelling}

The preliminary processing solutions were obtained by selecting common geometrical design models for the piston. The selected material properties during this study added to the simulation are: mechanical properties, linear elastic properties and experimental isothermal fatigue life consisting of alternating and mean stress with number of cycle data settled at a table in the solution.
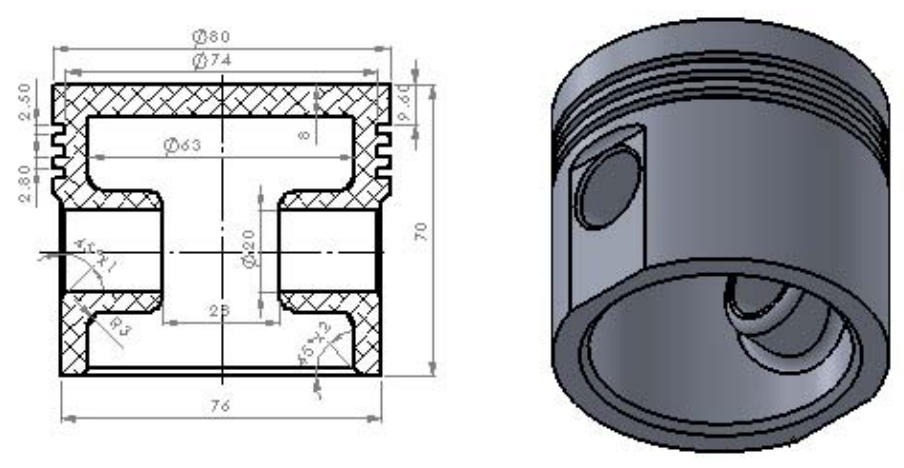

Fig.1a. The geometrical design modelling for a flat top piston. 
Three geometrical models of piston design were created using Solidworks 15, which is easy and has more tools to create models, depending on the sectional shape of the top surface of the piston. The designed models of piston were flat top surface, circular cut sectioning top surface and dome sectioning top surface as detailed in Figs 1a, 1b, and 1c. These models were imported into ANSYS Workbench 16.1 software. Due to the irregular geometric model, a CutCell method was used in the models that included elements, shapes and mesh patterns. The meshing was employed with total number of nodes (9286) and total number of elements (4891) as shown in Fig.2.
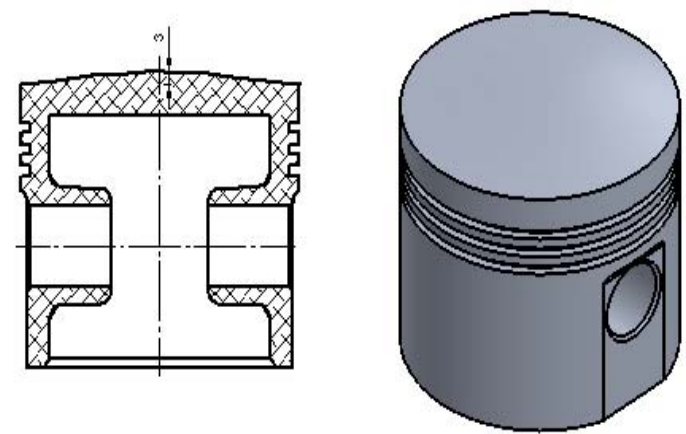

Fig.1a. The geometrical design modelling for a dome sectioning top piston.
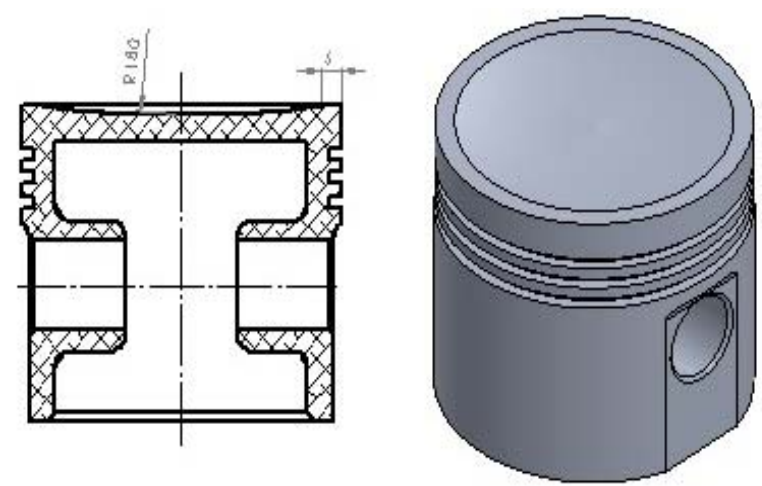

Fig.1b. The geometrical design modelling for a circular cut sectioning top piston

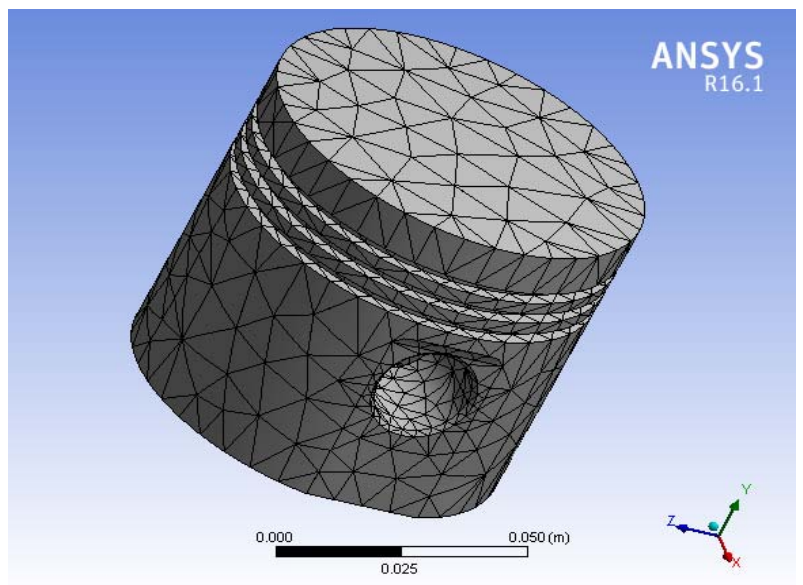

Fig.2.The piston meshing. 


\subsection{Boundary conditions specification}

The IC engine is subjected to different loading conditions. Therefore, it is important to consider the material properties and the possible scenarios of external loads and constraints, which are called boundary conditions. High strength aluminium alloy is a common type of material required for the internal combustion (IC) engine piston. In this study, the Al 7075-T6 alloy was selected as the piston material based on published research of Essam Fadhel [12]. The chemical composition and mechanical properties are detailed in Tabs 1 and 2, while the isothermal fatigue data generated experimentally at a constant elevated temperature of $225^{\circ} \mathrm{C}$ are listed in Tab.3. These properties and fatigue data were implemented in the numerical simulation for generating the material properties based on the experimental recorded data. The whole model including the element boundaries was affected by the mechanical loading described as a gas pressure subjected to the top of the piston combined with a steady state elevated temperature at $225^{\circ} \mathrm{C}$. So that the top surface of the piston suffered under thermo-mechanical loading.

Table 1. Chemical composition and mechanical properties of A17075-T6 aluminium alloy.

\begin{tabular}{|c|c|c|c|c|c|c|c|c|}
\hline Element & $\mathrm{Si} \%$ & $\mathrm{Fe} \%$ & $\mathrm{Cu} \%$ & $\mathrm{Mn} \%$ & $\mathrm{Mg} \%$ & $\mathrm{Cr} \%$ & $\mathrm{Zn} \%$ & $\mathrm{Al} \%$ \\
\hline Content & 0.018 & 0.05 & 1.7 & 0.013 & 2.65 & 0.216 & 5.5 & $\mathrm{Rem}$. \\
\hline
\end{tabular}

Table 2. Physical and mechanical properties of the aluminium alloy.

\begin{tabular}{|c|c|}
\hline Density, $\rho\left(\mathrm{kg} / \mathrm{m}^{3}\right)$ & 2810 \\
\hline Poisson's ratio & 0.33 \\
\hline Linear thermal expansion, $\alpha(\mathrm{l} / \mathrm{K})$ & $2.36 \cdot 10^{-5}$ \\
\hline Thermal conductivity, $k(\mathrm{~W} / \mathrm{m} . \mathrm{K})$ & 130 \\
\hline Specific heat, $c(\mathrm{~J} / \mathrm{kg} . \mathrm{K})$ & 760 \\
\hline Modulus of elasticity, $E(\mathrm{GPa})$ & 26.9 \\
\hline Modulus of rigidity, $\mathrm{G}(\mathrm{GPa})$ & 570 \\
\hline Ultimate tensile strength, $\sigma_{T}(\mathrm{MPa})$ & 505 \\
\hline Yield strength, $\sigma_{y}(\mathrm{MPa})$ & \\
\hline
\end{tabular}

Table 3. Stress number of cycle's data at constant elevated temperature of $225^{\circ} \mathrm{C}$.

\begin{tabular}{|c|c|}
\hline Stress $(M P a)$ & No. of cycles (cycle) \\
\hline 540 & 98 \\
\hline 480 & 869 \\
\hline 420 & 2168 \\
\hline 360 & 22803 \\
\hline 300 & 42999 \\
\hline 240 & 67555 \\
\hline
\end{tabular}

\subsection{Simulation solution}

A set of simultaneous systems of equations depending on mesh generation can be formulated using existing approaches. The general thermo-mechanical finite element simulation for the piston under constant 
pressure and steady-state elevated temperature as an isothermal fatigue case, applied to the exterior boundary can be achieved by solving the set of equations obtained from [13]. The conduction heat transfer temperature for a homogeneous and isotropic material regarding the nodal values can be obtained by the equation;

$$
\frac{\partial^{2} \boldsymbol{T}}{\partial \boldsymbol{x}^{2}}+\frac{\partial^{2} \boldsymbol{T}}{\partial \boldsymbol{y}^{2}}+\frac{\partial^{2} \boldsymbol{T}}{\partial \boldsymbol{z}^{2}}+\frac{\boldsymbol{Q}}{\boldsymbol{k}}=0
$$

The general form of the stress-strain relationship for a three-dimensional isotropic body under thermomechanical loading is found in many finite element studies [14]:

$$
\begin{aligned}
& {[\sigma]=[D]\left\{\int-\int_{\text {thermal }}\right\},} \\
& {\left[\begin{array}{l}
\sigma_{x x} \\
\sigma_{y y} \\
\sigma_{z z} \\
\tau_{x y} \\
\tau_{y z} \\
\tau_{z x}
\end{array}\right]=\frac{E}{(1+v)(1-2 v)}\left[\begin{array}{cccccc}
1-v & v & v & 0 & 0 & 0 \\
v & 1-v & v & 0 & 0 & 0 \\
v & v & 1-v & 0 & 0 & 0 \\
0 & 0 & 0 & \frac{1-2 v}{2} & 0 & 0 \\
0 & 0 & 0 & 0 & \frac{1-2 v}{2} & 0 \\
0 & 0 & 0 & 0 & 0 & \frac{1-2 v}{2}
\end{array}\right]\left\{\int-\int_{t h}\right\},} \\
& \left\{\int_{\text {thermal }}\right\}=\alpha T\left\{\begin{array}{l}
1 \\
1 \\
1 \\
0 \\
0 \\
0
\end{array}\right\} .
\end{aligned}
$$

Plastic von Mises stress distribution regarding the nodal values can be obtained by the equation

$$
\sigma_{V M}=\frac{\sqrt{\left[\left(\sigma_{x}-\sigma_{y}\right)^{2}+\left(\sigma_{y}-\sigma_{z}\right)^{2}+\left(\sigma_{z}-\sigma_{x}\right)^{2}\right]}}{2} .
$$

The stress intensity factors regarding the nodal values can be determined by the equations

$$
K_{I}=\sigma_{V M} Y \sqrt{\pi u} .
$$

\section{Results and discussion}

The numerical analysis focused on determining the thermo-mechanical strength of three shape designs of the IC engine piston that differ in the top face section. The strength analysis was conducted under the pressure loading range of $(5,10,15$ and $20 \mathrm{MPa})$ with constant elevated temperature of $225^{\circ} \mathrm{C}$, subjected to the top face of the piston. This analysis concentrated on finding the stress intensity with 
equivalent alternating stress and fatigue life, depending on the experimental isothermal fatigue recorded data. The results presented the stress intensity, which is based on von Mises stress, influenced by a range of pressure for different piston geometrical shapes. Figure 3 shows that increasing the mechanical load (pressure) on the piston top face increases the effect zones, especially at the top and bottom edges, which is the same for the other types of piston designs.
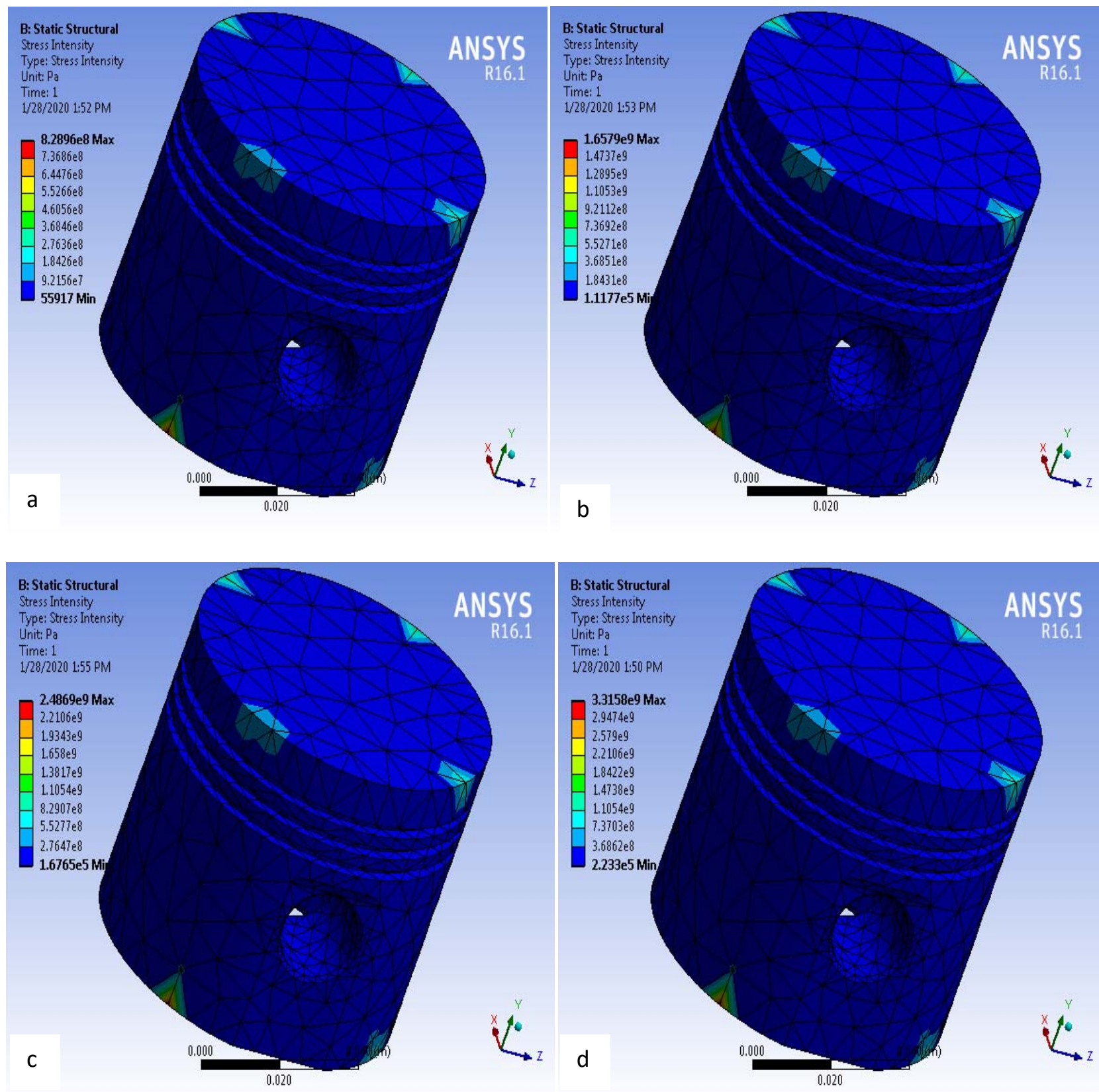

Fig.3. Stress intensity effects with pressure loading range on the piston of flat top face; a) $5 M P a$, b) $10 \mathrm{MPa}, \mathrm{c}) 15 \mathrm{MPa}, \mathrm{d}) 20 \mathrm{MPa}$.

Analysis of the geometrical shape design effects of the piston shows that the dome section model gives lower stress intensity (Fig.4.) for the circular cut and dome sectioning top face types under high thermo-mechanical loading. High stress intensity was initiated at the top and bottom faces sharp edges of the design model, 
causing a stress concentration, similar to the real failure shown in Fig.5 for dome and flat shape faced piston failures. The same results were achieved by other researchers $[7,9,11]$ revealing similarly effective stress zones on the piston edges during simulations.
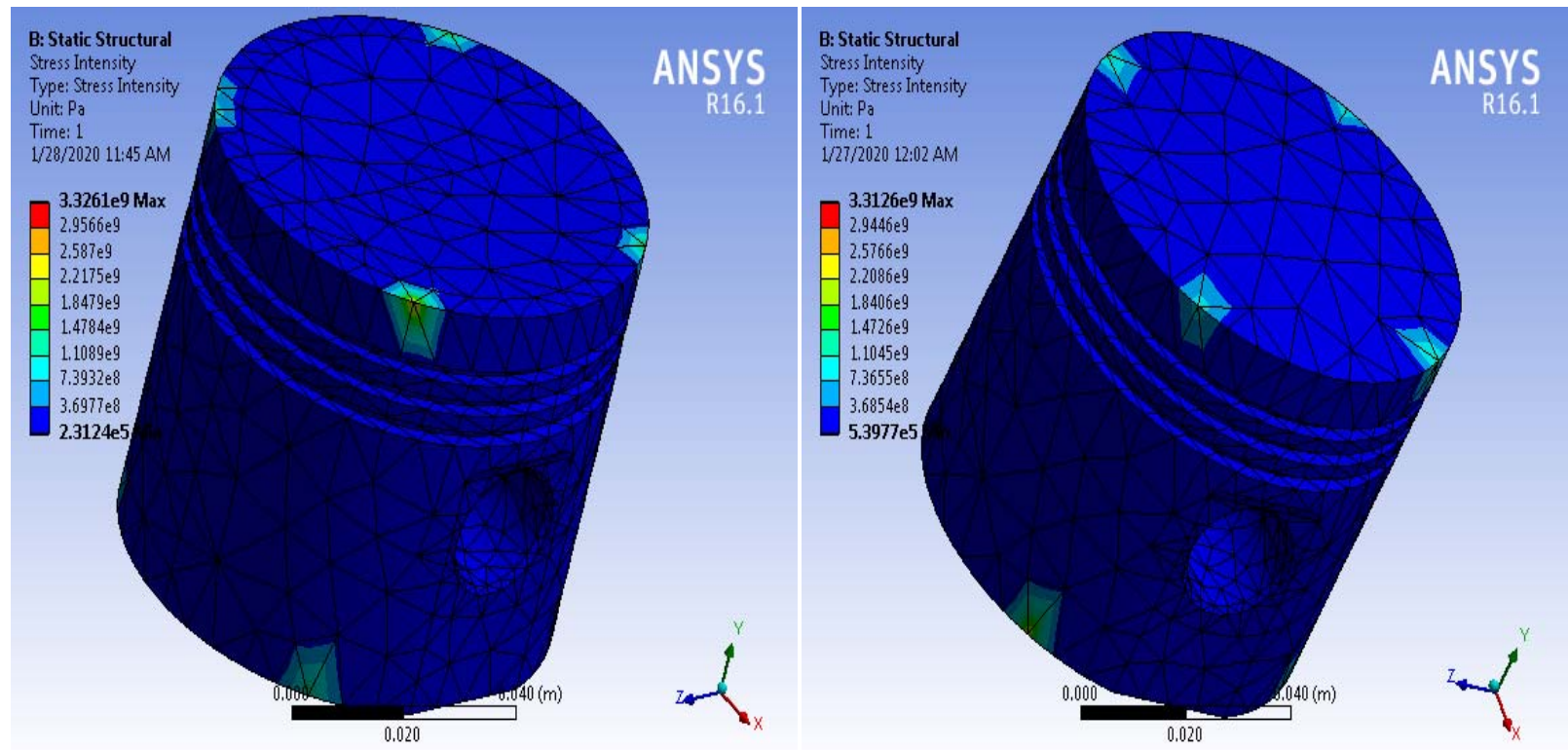

Fig.4. Stress intensity effects on, a) piston with circular cut section top face, b) piston with dome section top face.
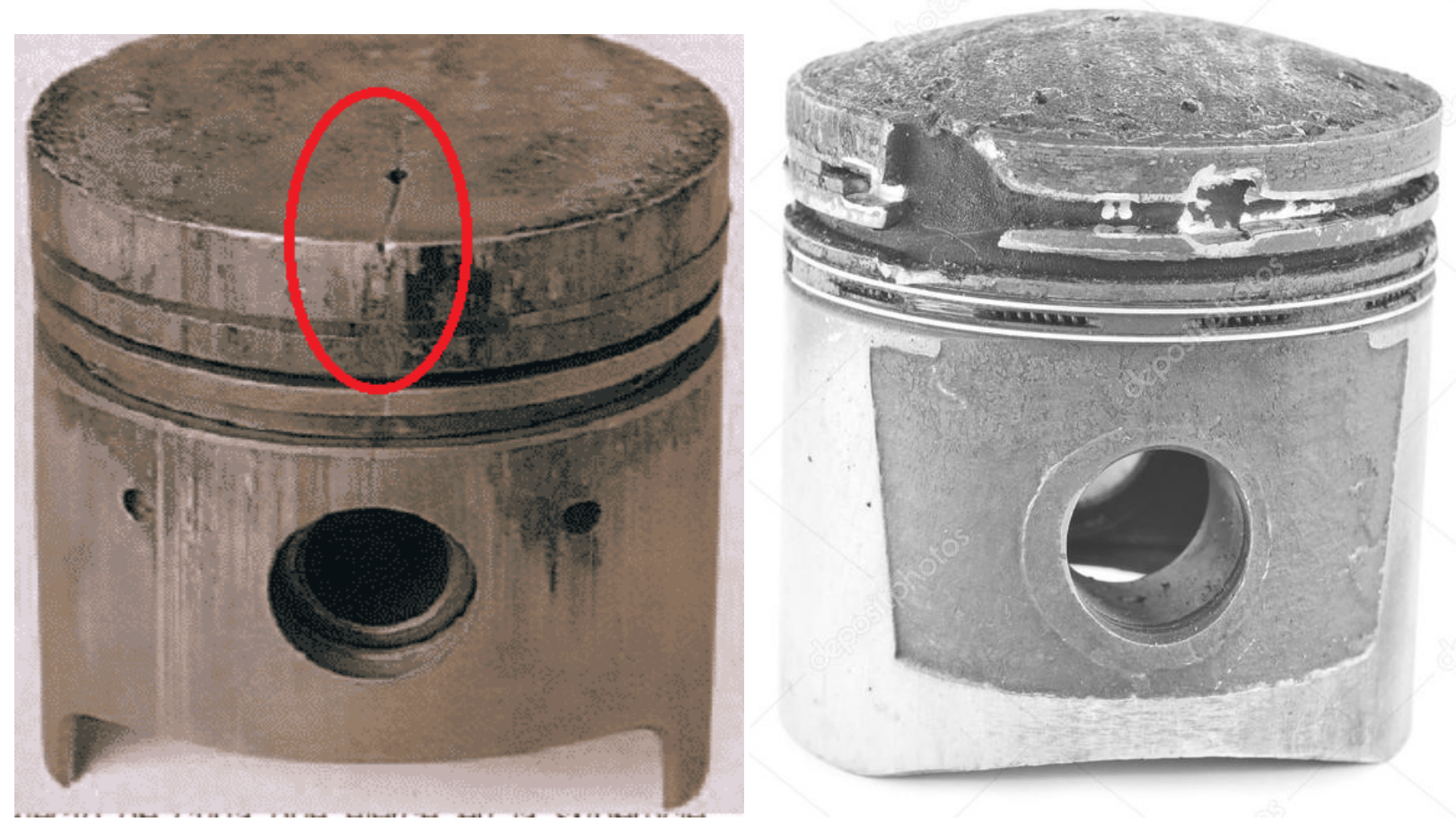

Fig.5. One of the real failures occurred in flat and dome shapes top faced pistons.

The fatigue life results show that the thermo-mechanical fatigue life decreases with increasing mechanical loading for the circular cut section of the top face of the piston shown in Fig.6. Similarly, other 
researchers $[7,9,11]$ reported that the effective stress occurred at the top surface and edges of the piston. According to the presented analysis, thermo-mechanical fatigue loading limit depends on the selected type of material and is very close to $5 \mathrm{MPa}$, where the highest compression ratio in the IC engine produces a pressure of about 3 to $4 \mathrm{MPa}$ at the end of compression stroke [15]. If the applied loads exceed this limit, then fatigue failure occurs as fatigue life zones. The dome and circular cut sectioning pistons show better fatigue life than the flat face piston design illustrated in Fig.7. Moreover, the fatigue initiation occurs at the bottom face edge of the flat and dome pistons due to the closest edge distance than the central position. In the circular cut sectioning, fatigue is initiated in the top face edge due to the effects of the curvature profile on the stress concentration. Based on fatigue simulation, the resulting equivalent alternating stresses increased with increasing pressure on the piston face (Fig.8.). Determination of the geometrical shape design effects shows that the dome face type has the lowest alternating stresses compared with other piston shapes, followed by the circular cut section, while the higher stress is the flat section face (Fig.9.). The fatigue life and stresses are due to the fact that elevated temperature reduces the mechanical properties of the material.
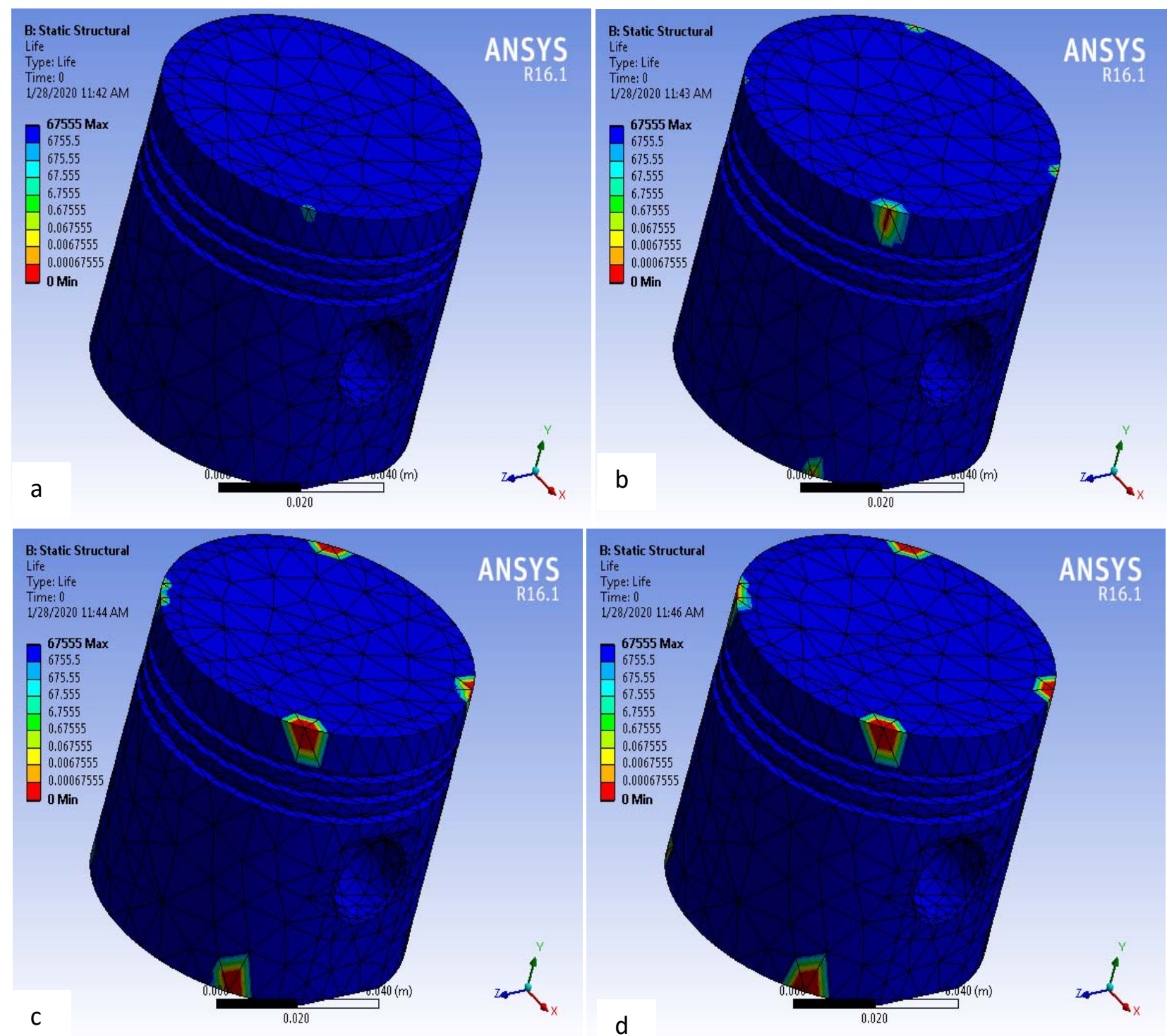

Fig.6. Thermo-mechanical fatigue life effects on the piston of circular section face with pressure loading range. a) $5 \mathrm{MPa}$, b) $10 \mathrm{MPa}$, c) $15 \mathrm{MPa}$, d) $20 \mathrm{MPa}$. 

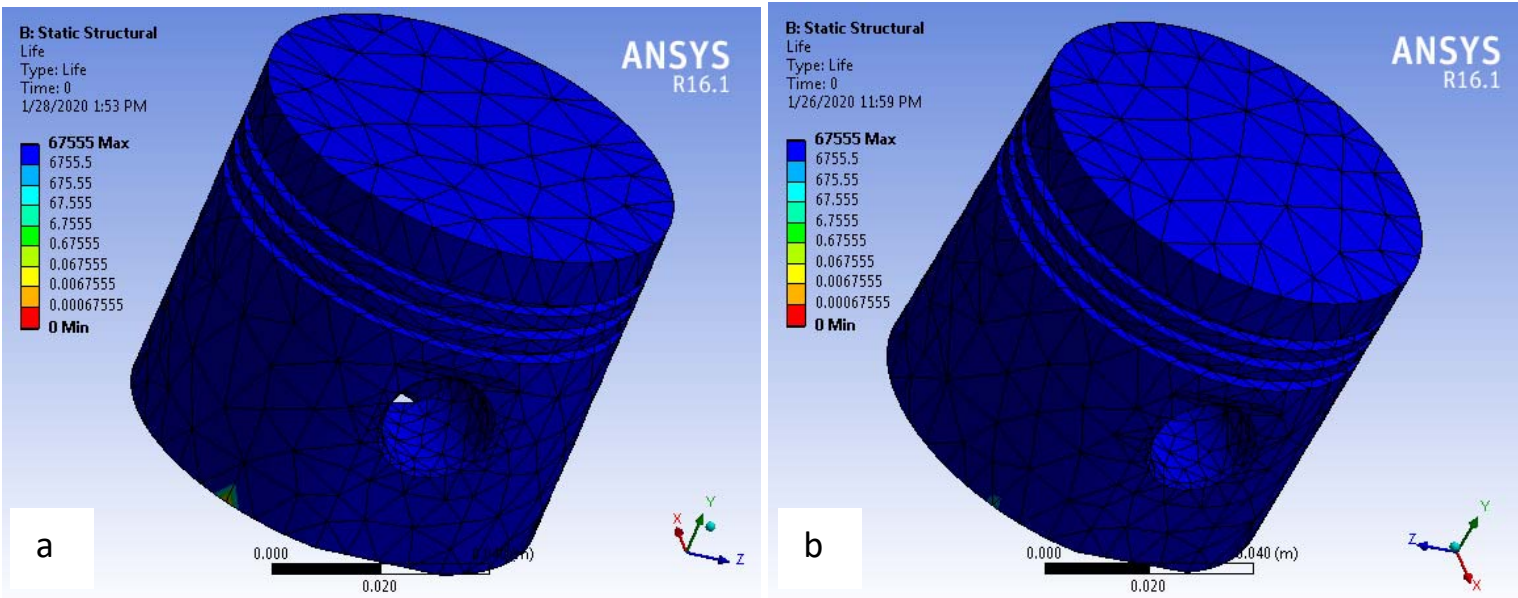

Fig.7. Thermo-mechanical fatigue life effects at pressure loading $5 \mathrm{MPa}$ on the a) piston with flat section top face, b) piston with dome section top face.
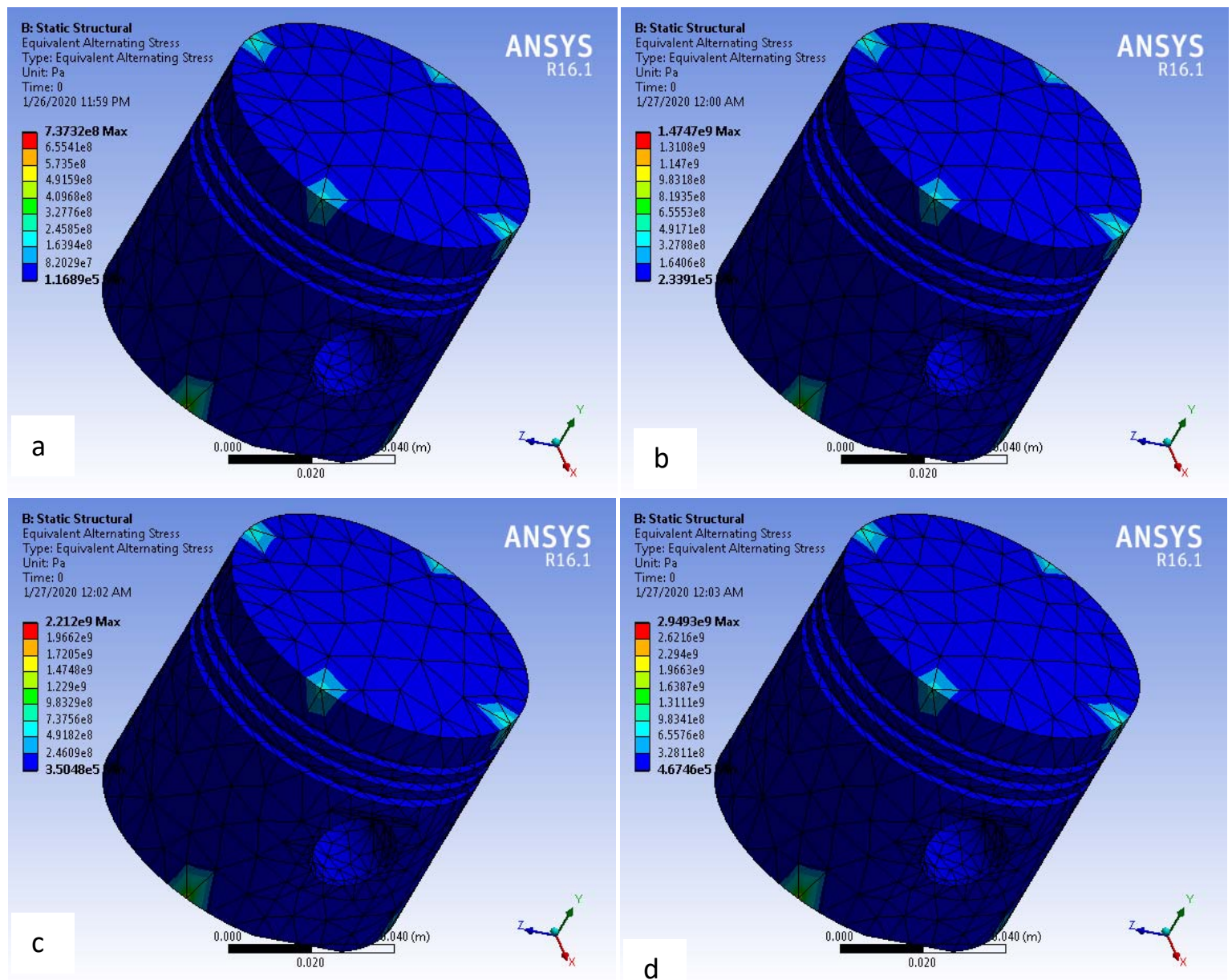

Fig.8. Fatigue equivalent alternating stress effects range on the piston of dome section face with pressure loading. a) $5 \mathrm{MPa}$, b) $10 \mathrm{MPa}$, c) $15 \mathrm{MPa}$, d) $20 \mathrm{MPa}$. 


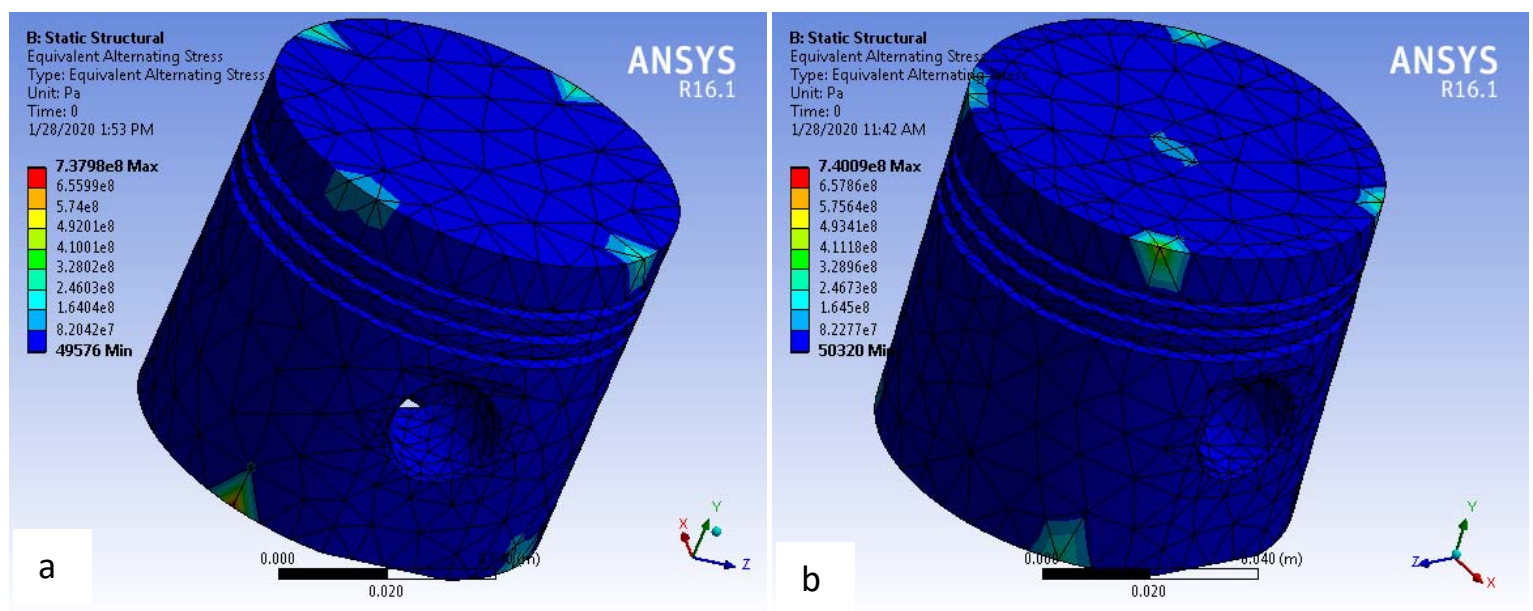

Fig.9. Fatigue alternating stress effects at pressure loading $5 \mathrm{MPa}$ on the a) piston with a flat section top face, b) piston with circular cut section top face.

\section{Conclusion}

A numerical modelling and simulation utilising ANSYS software was conducted to analyse the thermo-mechanical strength for different shape designs of the IC engine piston based on experimental elevated isothermal fatigue data. The thermo-mechanical loading was settled at elevated temperature of about $225^{\circ} \mathrm{C}$ and a range of high pressure applied to the top face of the piston. The results of the simulation indicated that the stress intensity and fatigue equivalent alternating stress increased with increasing pressure load. The fatigue life decreased until passing the failure loading limit. The geometrical shape design of the piston face significantly affected the strength and fatigue life. The dome piston shape had lower stress and higher fatigue life than the other piston shape designs.

\section{Nomenclature}

$$
\begin{aligned}
& {[D]-\text { material property matrix }} \\
& Q-\text { relevant quantity generated regarding the case boundary condition. } \\
& u-\text { displacement in three dimensions } \\
& Y-\text { shape factor } \\
& \alpha-\text { linear thermal expansion } \\
& \{\epsilon\}-\text { mechanical strain } \\
& \left\{\epsilon_{\text {thermal }}\right\} \text { - thermal strain }
\end{aligned}
$$

\section{References}

[1]Vaishali R. and Khamankar S.D. (2015): Stress analysis of piston using pressure load and thermal load.International Journal of Mechanical Engineering, vol.3, No.8, p.8.

[2] Nitin K., Srivastav, Ram P.S., Amit K., Girjesh Y., Rajoo S., Prashant K.M., Alok K.P. and Shyam B. (2015): Finite element analysis of piston head by ABAQUS.- Int. Journal of Scientific and Engineering Research, vol.6, No.5, pp.25-28.

[3] Lokesh S., Suneer S.R., Taufeeque H. and Upendra K. (2015): Finite element analysis of piston in ANSYS.International Journal of Modern Trends in Engineering and Research, vol.2, No.4, Corpus ID: 34926816 
[4] Sandeep K.K. and Vishnu B.G. (2015): Design and analysis of piston by using finite element analysis.- Int. Journal of Eng. Res. And Tech., vol.4, No.9, pp.296-301.

[5] Mallavarapu N. and Vijaya K. (2015): Thermal \& static analysis on IC engine piston using FEA.- International Journal of Advance Research in Science and Engineering, vol.4, No.12, pp.244-250.

[6] Andoko Doko and Poppy P. (2016): Finite element analysis of surface tension on piston due to pressure variation.Proc. of the Int. Mech. Eng. And Edu. Conf., (IMEEEC 2016), AIP Conference Proceedings 1778, 030064.

[7] Cioată V.G., Kiss I., Alexa V. and Rațiu S.A. (2017): Mechanical and thermal analysis of the internal combustion engine piston using Ansys.- International Conference on Applied Sciences (ICAS2016), IOP Conf. Series: Materials Science and Engineering, vol.163, manuscript number 012043.

[8] Manish K. (2018): A finite element thermo-mechanical stress analysis of IC engine piston.- International Research Journal of Engineering and Technology (IRJET), vol.4, No.6, pp.1976-1981.

[9] Valentin M. (2018): Static and thermal analysis of piston using FEM analysis.- Int. Jr. for Res. In Applied Sci. \& Eng. Tech., vol.6, No.1, pp.201-206.

[10] Syed A.A., Nalla S. and Elumagandla S. (2018): Static and thermal analysis of piston with different thermal coatings.- International Research Journal of Engineering and Technology (IRJET), vol.5, No.10, pp.1255-1267.

[11] Ajay, Arshad M., Abhishek K.S. and Ankit K. (2018): Numerical validation of thermal analysis of an automobile piston using ANSYS.- International Journal of Research in Engineering and Innovation, vol.2, No.4, pp.384-391.

[12] Essam Z.F. (2018): Effect of the elevated temperature on fatigue behaviour of aluminium alloy AA 7075.- Journal of University of Babylon for Engineering Sciences, vol.26, No.8, pp.256-264.

[13] Liu G.R and Quek S.S. (2003): The Finite Element Method: A Practical Course.- Elsevier Science Ltd, First published.

[14] Zhangxin Chen (2011): The Finite Element Method.- World Scientific Publishing Co. Pte. Ltd.

[15] Giri N.K. (2006): Automobile Mechanics.- KHANNA Publishers, Delhi, India, Eight Edition.

Received: December 31, 2020

Revised: March 29, 2021 